\title{
Mandado de Segurança
}

Impetrante, usuário do tabaco, pretende ter assegurado o direito de fazer uso do fumo em shopping centers, livre do pagamento da multa estabelecida pelas Leis Municipais ns. 9.120/80, 11.657/94 e 9.178/95, bem como pelos Decretos Municipais ns. $1.745 / 81$ e 34.386/95.

Tribunal de Justiça do Estado de São Paulo

Apelação Civel n. 030.032-5/9-00

Relator: Ribeiro Machado

Data da decisão: 4.8.1998

\section{ACÓRDÃO}

Vistos, relatados e discutidos estes autos de Apelação Civel n. 030.032-5/9-00, da Comarca de São Paulo, em que é recorrente o Juízo Ex Officio, sendo apelante Prefeitura Municipal de São Paulo e apelado Fúlvio João Smilari:

Acordam, em Terceira Câmara de Direito Público do Tribunal de Justiça do Estado de São Paulo, por votação unânime, dar provimento aos recursos, de conformidade com o relatório e voto do Relator, que ficam fazendo parte do acórdão.

O julgamento teve a participação dos Desembargadores Márcio Bonilha e Hermes Pinotti.

São Paulo, 4 de agosto de 1998.

Apelação Cível n. 030.032-5/9-00, Voto n. 8.212, Comarca de São Paulo, Apelantes: Prefeitura Municipal de São Paulo e outro, Apelado: Fulvio João Smilari. Relator: Ribeiro Machado.

Mandado de Segurança - Impetrante, usuário do tabaco, pretende ter assegurado o direito de fazer uso do fumo em shopping centers, livre do pagamento da multa estabelecida pelas Leis Municipais ns. 9.120/80, 11.657/94 e 9.178/95, bem como pelos Decretos Municipais ns. $1.745 / 81$ e $34.386 / 95$.

O tabagismo enquadra-se com problema de saúde pública, em razão de seu fator cancerígeno e de gerador de riscos de doenças e outros agravos contra o individuo e a coletividade. O maleficio também alcança os denominados "fumantes passivos". 
A legislação municipal que restringe o uso de produtos fumigeros em recinto coletivo, está fundamentada na competência que a Constituição Federal Ihe atribui para suplementar a legislação federal e estadual no setor de proteção e defesa da saúde: Arts. 24, XII e 30, II da Constituição estadual; Lei Orgânica do Municipio de São Paulo, art. 213.

Os preceitos legais do Municipio de São Paulo sobre as restrições ao uso de produtos fumigeros, passaram a integrar todas as determinações da recente legislação federal especifica, da Lei $n$. 9.294/96 e Decreto n. 2.018/96, este ressalvando expressamente a validade das sanções previstas na legislação local.

Recursos providos para reformar a sentença que concedeu a segurança.

Ao relatório da r. sentença de fls. 147/151, que se adota, acrescenta-se que foi parcialmente concedida a ordem impetrada por Fulvio João Smilari contra ato do Sr. Secretário das Administrações Regionais Municipais de São Paulo, apenas porque o impetrante possa exercer o seu direito ao tabagismo em restaurantes de São Paulo, devendo a autoridade impetrada se abster de atuar o impetrante com fulcro nas Leis ns. 9.120/80, 11.657/94, bem como com fundamento nos Decretos ns. 17.451/ 81 e 29.014/94, revogando parcialmente a liminar concedida. Outrossim, cada parte foi condenada ao pagamento de $50 \%$ das custas e despesas processuais, atualizadas, sem condenação em verba honorária (Súmula n. 512 STF).

O MM. Juiz sentenciante determinou o reexame necessário.

Apela a Prefeitura Municipal de São Paulo, para tanto sustentando a competência municipal para tratar da matéria, qual seja, saúde pública. Informa, também que a legislação municipal que restringe o hábito do tabagismo obedece a um sistema legal desde a edição da Lei n. 3.939/89. Depende, ainda, a legalidade e a constitucionalidade das Leis ns. 9.120/ 80 e $11.657 / 94$ e, conclui, a legislação estadual tem alcance limitado, não podendo admitir-se a invasão da competência municipal, mormente em face do principio constitucional da autonomia municipal.

Apelação tempestiva, recebida e respondida.

Manifesta-se o Ministério Público às fls. 170/181 e através de parecer da d. Procuradoria geral de Justiça às fls. 189/191, pelo qual opina pelo improvimento dos recursos.

É o relatório.

Pela via do mandado de segurança, o impetrante, que se diz tabagista, pretende ter reconhecido o seu direito de fazer uso do fumo em 
shopping centers e em restaurante, mas livre da multa estabelecida pelas Leis Municipais ns. 9120/80, modificada pela Lei Municipal n. 11.657/94, regulamentadas pelos Decretos ns. 17.451/81 e 29.014/90.

Aduz que o Município não tem competência para legislar sobre a matéria referente a cidadania, saúde pública e meio ambiente. Destaca, ademais, que os referidos diplomas legais estão em conflito com a Lei Estadual n. 9.178/95. Observa, finalmente, que somente através de previsão de Lei Complementar o Município teria competência para ditar normas, relativas à poluição e à saúde de seus municipes.

A ordem foi concedida em parte, alcançando apenas o direito do impetrante fazer uso do tabaco em restaurante do Municipio de São Paulo, imune ás multas previstas pela legislação municipal destacada.

A r. sentença recorrida não prevalece, razão pela qual fica reformada.

A Constituição Federal dispõe em seu artigo 196: "A saúde é direito de todos e dever do estado, garantido mediante politicas sociais e econômicas que visem à redução do risco de doença e de outros agravos e ao acesso universal e igualitário às ações e serviços para sua promoção, proteção e recuperação".

A respeito, José Afonso da Silva observa:

"A saúde é concebida como direito de todos e dever do Estado, que a deve garantir mediante politicas sociais e econômicas que visem à redução do risco de doença e de outros agravos". (...) "As ações e serviços de saúde são de relevância pública, por isso ficam inteiramente sujeitos à regulamentação, fiscalização e controle do Poder Público, nos termos da lei, a que cabe executá-los diretamente ou por terceiros, pessoas físicas ou juridicas de direito privado."

E conclui o ilustre constitucionalista:

"Se a Constituição atribui ao Poder o controle das ações e serviços de saúde, significa que sobre tais ações e serviços tem ele integral poder de dominação, que é o sentido do termo controle, mormente quando aparece ao lado da palavra fiscalização." (in "Curso de Direito Constitucional Positivo", p. 707/708 da 9 9 $^{\text {ed., }} 4^{\text {a }}$ tiragem, Malheiros editores).

A Carta Magna, quando trata da Organização Politico-Administrativa do estado, estabelece:

Art. 23. É competência comum da União, dos Estados, do Distrito Federal e dos Municipios: 
II - cuidar da saúde e assistência pública, proteção e garantia das pessoas portadoras de deficiência;

Art. 24. Compete à União, aos Estados e ao Distrito Federal legislar concorrentemente sobre:

XII - previdência social, proteção e defesa da saúde;

No mesmo Título II, no Capítulo IV, ao tratar dos Municipios, dispõe:

"Art. 30. Compete aos Municipios:

I - (omissis)

II - suplementar a legislação federal e estadual no que couber. Federal.

A Constituição Estadual seguiu os preceitos ditados pela Constituição

Assim, após estabelecer em seu artigo 219 que: "A saúde é um direito de todos e dever do Estado", no parágrafo único do mesmo dispositivo, reza: "Parágrafo único - O Poder Público Estadual e Municipal garantirão o direito à saúde mediante: I - politicas sociais, econômicas e ambientais que visem ao bem-estar físico, mental e social do individuo e da coletividade e à redução do risco de doenças e outros agravos."

A Lei Orgânica do Municipio de São Paulo, em harmonia com a autonomia municipal, estabelece:

Art. 213. O Municipio, com participação da comunidade, garantirá o direito à saúde:

1 - mediante politicas que visem ao bem estar físico, mental e social do individuo e da coletividade, a redução e a busca da eliminação do risco de doenças e outros agravos, abrangendo o ambiente natural, os locais públicos e de trabalho.

O nosso sistema constitucional estabelece que o assunto envolvendo a proteção e defesa da saúde, está sujeito à disciplina por normas federais, estaduais e municipais, segundo a competência comum prevista no artigo 23, II, da Constituição Federal.

A respeito do tema, Hely Lopes Meirelles ensina:

"Os serviços de saúde pública, higiene e assistência social incluemse na categoria das atividades comum às três entidades estatais 
que, por isso, podem provê-los em caráter comum, concorrente ou supletivo (CF, art. 23, II e IX)" (in "Direito Brasileiro", p. 326 da 8" ed., 1990, Malheiros)

O saudoso mestre, a respeito das competências concorrentes e supletivas (CF, arts. 30, 24, XII e art. 30, II) faz as seguintes considerações:

"Tratando-se de competências concorrentes e supletivas, sempre que a esfera mais alta passar a prover o mesmo assunto de modo diverso do provimento inferior, fica afastada a regulamentação da entidade menor; as não houver conflitos, vigem, paralelamente, ambas as competências." (obra citada, 327)

O tabagismo enquadra-se como problema de saúde pública, em razão de seu fator cancerígeno e do risco de doenças e outros agravos contra os individuos e a coletividade como um todo.

Os malefícios causados alcançam não só os usuários do tabaco, mas também os denominados "fumantes passivos", que estão em ambientes alcançados pela fumaça exalada pelos produtos fumígeros.

A questão é pacifica na medicina e já é do conhecimento popular. Nesse sentido, basta lembrar advertências obrigatórias consignadas em toda propaganda de cigarros.

Ademais disso, pesquisas realizadas junto à população em âmbito nacional, estadual e municipal indicam que a maioria das pessoas manifestam-se contrariamente ao uso de tabaco em ambientes fechados, inclusive nos bares e restaurantes.

Assim, a disciplina do uso do tabaco em recintos coletivos constitui medida de higiene pública, pois como ensina Hely Lopes Meirelles:

"A higiene pública é, em última análise, o asseio da cidade. Condição primeira para a salubridade da população é a cidade limpa. Essa limpeza vai desde a varrição e lavagem das vias e logradouros públicos, a coleta de lixo, a condição das águas pluviais, as redes de água potável e de esgotos, a desinfecção de locais insalubre e veículos de transporte coletivo, o desmatamento de terrenos baldios, a limpeza das margens de rios e lagos, o combate a animais nocivos, a drenagem de charcos, a purificação do ar respirável, o tratamento das águas utilizáveis, o controle das atividades poluidoras, até a inspeção dos gêneros oferecidos ao consumo da população local."

E conclui o festejado mestre:

"Para tanto, o Municipio dispõe do poder de polícia necessário à fiscalização sanitária das coisas e locais, públicos ou particulares, 
que devam manter-se higienizados, em benefício da salubridade coletiva, podendo impor as sanções cabiveis, na forma regulamentar" (in "Direito Municipal Brasileiro", p. 345 da 8ª ed., 1990. Malheiros).

No município de São Paulo, vêm sendo editados diplomas legais restringindo o uso de produtos fumigeros em ambientes utilizados pelo público. Assim já em, 1950 a Lei n. 3.938 passou a proibir o fumo em veículos de transporte coletivo, elevadores de passageiros e salas de espetáculos. Na seqüência, outras leis municipais foram sancionadas, na linha da restrição do tabagismo, dentre as quais se destacam a Lei $n$. $9.120 / 80$ e a Lei n. $10.862 / 90$, às quais está vinculado o questionado Decreto Municipal n. 34.836, de 31.1.95, que regulamentou a Lei n. 10.862/ 90 , relativamente aos bares, restaurantes e similares.

Essa legislação não proíbe as pessoas de fumar, apenas restringe a prática do fumo no s locais especificados, freqüentados por usuários que neles buscam o consumo de alimentos e mesmo de bebidas.

A Lei n. 9.120/80, de 8 de outubro de 1980, traça preceitos de ordem geral, estabelecendo:

"Art. 10 É proibido fumar em estabelecimentos fechados, onde for obrigatório o trânsito ou a permanência de pessoas, assim considerados, entre outros, os seguintes locais."

Nos incisos do dispositivo, são discriminados os locais, como elevadores, interior de meios de transportes coletivos urbanos, dependências de hospitais, creches, postos de saúde, auditórios, museus, teatros, estabelecimentos de ensino de $1^{\circ}$ e $2^{\circ}$ Graus, garagens de prédios públi$\cos$ e edificios comerciais e residenciais, interior de veículos destinados a serviços de táxi etc.

Dentre esses locais, está incluido:

"VI — o interior de estabelecimento comerciais".

A mesma lei estabeleceu em seu artigo $3^{\circ}$ que:

"os órgãos e os estabelecimentos abrangidos nesta lei, poderão dispor de salas ou recintos destinados exclusivamente aos fumantes, desde que abertos ou ventilados, atendidas as recomendações oficiais quando as medidas de prevenção contra incêndio."

Após a edição do Decreto Municipal n. 9.179, de 17 de novembro de 1995, que "Estabelece restrições ao tabagismo nos estabelecimentos comerciais que especifica", dispondo: 
"Art. 1ㅇ Os restaurantes, bares, churrascarias, lanchonetes e estabelecimentos comerciais afins, no âmbito do Estado, que possuam área superior a $100(\mathrm{cem}) \mathrm{m}^{2}$, ficam obrigados a dispor de espaço reservado às pessoas não fumantes.

Parágrafo único. O espaço a que se refere o caput deste artigo não poderá ser inferior a $50 \%$ (cinqüenta por cento) da área de consumação ao público.

Art. 2\% Ficam dispensados da obrigatoriedade a que se refere o artigo anterior, as casas noturnas de diversão e lazer, tais como casa de dança, boates, casas de música, casas de Shows e congêneres que, também, efetuem manipulação, consumo e venda de alimentos.

Art. 4\% Para os efeitos desta lei consideram-se infratores os fumantes e os estabelecimentoa nela abrangidos, nos limites da responsabilidade que Ihe é atribuida" (fls. 262)

A Lei estadual foi regulamentada pelo Decreto n. 40.695 , de 4 de março de 1996 (fls. 263), que repetiu os dispositivos da lei regulamentadora, inclusive quanto à penalidade, dispondo:

Art. $5^{\circ}$ Os infratores às disposições deste decreto ficarão sujeitos à penalidade de multa de 40 (quarenta) UFESP — Unidade Fiscal do estado de São Paulo vigente, dobrando a multa em casos de reincidência.

Ficou definido o encargo de controle e fiscalização:

Art. 6 $\mathrm{O}$ controle e a fiscalização do cumprimento das determinações deste decreto e a aplicação das sanções previstas no artigo anterior serão realizados pelas Vigilâncias sanitárias das Direções Regionais de Saúde em complementação às atribuições das Vigilâncias Sanitárias do Municipio.

Em termos de legislação, na seqüência do tempo, foi sancionada a Lei Federal n. 9.294, de 15 de julho de 1996 (fls. 286) que, verbis: "Dispõe sobre as restrições ao uso e à propaganda de produtos fumigeros, bebidas alcoólicas, medicamentos, terapias e defensivos agricolas, nos termos do $\S 4^{\circ}$ do art. 220 da Constituição Federal".

Esse diploma legal também dispõe a respeito do tabagismo:

"Art. $2^{\circ}$ É proibido o uso de cigarros, cigarrilhas, charutos, cachimbos ou de qualquer outro fumigero, derivado ou não do tabaco, em recinto coletivo, privado ou público, salvo em área destinada exclusivamente a esse fim, devidamente isolada e com arejamento conveniente." 
$\S 1^{\circ}$ Incluem-se nas disposições deste artigo as repartições públicas, os hospitais e postos de saúde, as salas de aula, as bibliotecas, os recintos de trabalho coletivo e as salas de teatro e cinema.

O Decreto federal n. 2.018 , de $1^{\circ}$ de outubro de 1996 , que regulamentou a Lei n. 9.294, de 15 de julho de 1996, estabeleceu:

"Art. 2 Para os efeitos deste Decreto são adotadas as seguintes definições:

I. Recinto coletivo: local fechado destinado à permanente utilização simultânea por várias pessoas, tais como casas de espetáculos, bares, restaurantes e estabelecimentos similares. São excluidos do conceito os locais abertos ou ao ar livre, ainda que cercados ou de qualquer forma delimitados em seus contornos;

II. Recintos de trabalho coletivo: as áreas fechadas em qualquer local de trabalho, destinadas à utilização simultânea por várias pessoas que nela exerçam, de forma permanente, suas atividades;

III. Aeronaves e veículos de transporte coletivo: aeronaves e veículos como tal definidos na legislação pertinente, utilizados no transporte de passageiros, mesmo sob forma não remunerada.

IV. Área devidamente isolada e destinada exclusivamente a esse fim: a área que no recinto coletivo for exclusivamente destinada aos fumantes, separada da destinada aos não-fumantes por qualquer meio ou recurso eficiente que impeça a transposição da fumaça.

Art. $3^{\circ} \dot{E}$ proibido o uso de produtos fumígeros em recinto coletivo, salvo em área destinada exclusivamente a seus usuários, devidamente isolada e com arejamento conveniente.

Parágrafo único. A área destinada aos usuários, de produtos fumigeros deverá apresentar adequadas condições de ventilação, natural ou artificial, e de renovação do ar, de forma a impedir o acúmulo de fumaça no ambiente.

Art. $4^{\circ}$ omissis

Art $5^{\circ}$ omissis

Art. $6^{\circ}$ A inobservância do disposto neste decreto sujeita o usuário de produtos fumigeros à advertência e, em caso de recalcitrância, sua retirada do recinto por responsável pelo mesmo, sem prejuizo das sanções previstas na legislação local. (o grifo é nosso).

Confrontando a Lei Federal n. 9.294/96 com as Leis Municipais ns. $9.120 / 80$ e $10.862 / 90$, verifica-se que aquela encampou os preceitos proibitivos da legislação municipal, até de forma mais ampla e rigorosa. 
Nesse sentido, ficou proibido em nivel nacional o uso de tabaco em qualquer recinto coletivo, privado ou público. Como recinto coletivo, foram considerados: bares, restaurantes e estabelecimentos similares.

Com exceção, foi admitido o uso de produtos fumigeros somente em área destinada exclusivamente a seus usuários, devidamente isolada e com arejamento conveniente.

Destarte, ficou admitida a área reservada exclusivamente para fumantes, disciplinada pelas legislações federal, estadual e municipal, já referidas.

Conseqüentemente, os recintos coletivos, nele incluidos os bares, restaurante e similares, que não tenham condições de destinar a área minima para os fumantes, estão incluídos no preceito proibitivo de âmbito federal, estadual e municipal.

Como já foi assinalado, a Constituição Federal atribui aos Municipios a competência para suplementar a legislação federal e estadual, relativamente à proteção e defesa da saúde.

A respeito, Hely Lopes Meirelles anota:

"No nosso sistema constitucional os assuntos de saúde e assistência pública ficam sujeitos à triplice regulamentação federal, estadual e municipal, por interessar simultaneamente a todas as entidades estatais. É o que se infere do texto e do espírito da CF, nos termos do art. 23, II, que estabelece a competência executiva comum da União, dos Estados e Município". ("Direito Administrativo Brasileiro", p. 126, da 20 ed., 1990, Malheiros Editores).

A respeito da competência especifica do Municipio, o mesmo mestre do Direito Administrativo ensina:

"Ao Municipio sobram poderes para editar normas de preservação da saúde pública, nos limites de seu território, uma vez que, como entidade estatal que é, está investido de suficiente poder de policia inerente a toda a Administração Pública, para a defesa da saúde e bem-estar dos municipes. Claro é que o Municipio não pode legislar e agir contra as normas gerais estabelecidas pela União e pelo Estado-membro ou além delas, mas pode supri-las na sua ausência, ou complementá-las em suas lacunas, em tudo que disser respeito à saúde pública local (CF arts. 24; XII e $30 \mathrm{I}$, II e VIII)" (in "Direito Municipal Brasileiro", p. 326, da $8^{\mathrm{a}}$ ed., 1990, Malheiros Editores)

Com relação à convergência de competências prevista na Carta Magna, Ives Gandra faz a seguinte observação:

"A competência comum, diferentemente da concorrente e da privativa, é competência que os entes federados exercem sobre a mesma 
matéria, sem todavia, interferir nas áreas de respectiva atuação, sobre não haver, em seu exercício ordinário hierarquia de exclusão." ("Comentários à Constituição do Brasil", Saraiva, 1992, vol. 3, T. I, p. 373/374).

Prevalente, portanto, a legislação do Municipio de São Paulo na parte da disciplina do uso do fumo, mesmo porque agora totalmente convalidada e referendada pela Lei Federal n. 9.294/96 e pelo Decreto regulamentar, com os quais em nada conflita.

Desta forma, em razão da edição de lei estadual e de lei federal, disciplinando a mesma matéria ligada ao interesse da saúde pública, não pode ser entendida como revogada a legislação municipal que é suplementar, por norma constitucional.

Válida, portanto, a sanção prevista na legislação municipal, à qual aderiu a legislação estadual, isso porque a mesma sanção decorre do exercicio do Poder Regulamentar de Polícia do Municipio.

Nesse sentido observa Hely Lopes Meirelles:

"No âmbito municipal, respeitados os assuntos da competência da União (...) supletiva do Estado-membro (...) remanesce para o Município a polícia sanitária local em todos os assuntos de seu interesse, concernentes à higiene da cidade e ao abastecimento de sua população (CF, art. 30. VII)"

No que diz respeito aos infratores, o decreto Municipal n. 34.836/95, estabelece: "Art. 50 Pelo descumprimento do disposto neste decreto, considera-se infrator tanto o estabelecimento quanto o fumante" (cf. fls. 19).

No mesmo sentido, foi o disposto pelo Decreto Estadual n. 40.695/ 96, ao estabelecer: "Art. 4 Para efeitos deste decreto consideram-se infratores os fumantes e os estabelecimentos nele abrangidos, nos limites da responsabilidade que thes é atribuida". (fls. 263).

A sanção aos infratores fumantes é necessária e mesmo imperiosa, porque garante o respeito e a obediência ao preceito proibitivo legal e se apóia no Poder de Polícia do Municipio. Sem a sanção, ficará comprometida a coercibilidade do preceito legal.

Quanto aos estabelecimentos, a sanção os alcança em razão da obrigação que possuem de zelar pela saúde e bem estar dos seus freqüentadores, preceitos esses inerentes às próprias atividades que devem ser executadas, resguardando o bem estar físico e mental dos usuários, reduzindo os riscos de doenças e de outros agravos, como estabelecem os diplomas legais estaduais e municipais referidos. 
Como já foi dito cabe ao Poder Público zelar pela saúde pública, direito de todos. Desse modo, pode e mesmo deve estabelecer preceitos de controle e de fiscalização, destinados a prevenir risco de doença e outros agravos. rido.

Contra normas de defesa da saúde pública não existe direito adqui-

Nesse sentido tem sido a lição deste Egrégio Tribunal de Justiça:

"Os princípios de polícia sanitária, sempre em evolução, na medida das exigências sócias, não conferem direito adquirido, em face da lei anterior." (in RT 66/84).

Essa orientação vem sendo reiterada por decisões mais recentes:

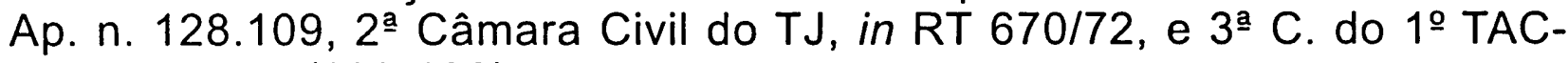
$\mathrm{SP}$, in RT 559/129-130).

Em suma, a r. sentença recorrida fica reformada, denegando-se a segurança, com a conseqüente cassação da limiar. Custas e despesas processuais serão arcadas exclusivamente pelo impetrante.

Isto posto, dá-se provimento aos recursos voluntário e oficial.

Relator: Ribeiro Machado

\section{COMENTÁRIOS}

Ruy Laurenti* ${ }^{* *}$

Trata-se de processo referente à Apelação Civil do Tribunal de Justiça de São Paulo.

Diz respeito a um indivíduo que ingressou na Justiça de São Paulo com um Mandato de Segurança pretendendo valer seus direitos de fumante. Entendia ele que eram ilegais as restrições impostas aos fumantes, principalmente em Shopping Centers, as quais implicam, conforme leis municipais, em pagamento de multa.

Em Primeira Instância ele ganhou a Segurança, sendo-Ihe garantido o direito de fumar. Houve apelação daquela decisão ao Tribunal de Justiça de São Paulo, onde se considerou a preponderância do interesse coletivo face ao individual, reformando-se assim a decisão.

Importante a se destacar é a questão da preponderância do interesse coletivo sobre o individual, nesse caso em uma questão relativa ao hábito de fumar. É de se destacar, entretanto, que essa decisão nos leva aos mais diversos tipos de ocorrências e, apenas como um exemplo, pode-

(*) Professor Titular do Departamento de Epidemiologia da Faculdade de Saúde Pública da Universidade de São Paulo-FSPIUSP. E-mail: laurenti@usp.com 
se citar o fato de certos estabelecimentos cujas atividades produzem barulho intenso perturbando os moradores vizinhos. Numerosos outros exemplos poderiam ser citados.

Outro aspecto que merece destaque no presente caso é o referente ao, assim chamado, "fumante passivo". Sabe-se hoje que esses sofrem a ação deletéria do fumo e não é nada justo, muito pelo contrário, que o interesse individual os prejudique.

No meu entender, a decisão do Tribunal de Justiça de São Paulo é digna de todos os elogios e deixa muito clara a preponderância do interesse coletivo em relação ao indivíduo. 